\title{
Repercussões psicológicas em adultos ante expectativa de acometimento pelo Corona
} vírus

\author{
Psychological repercussions in adults before the expectation of being affected by the Corona virus \\ Repercusiones psicológicas en adultos por la expectativa de ser afectados por el Corona virus
}

Recebido: 22/03/2021 | Revisado: 31/03/2021 | Aceito: 05/04/2021 | Publicado: 15/04/2021

\author{
Adelma do Socorro Gonçalves Pimentel \\ ORCID: https://orcid.org/0000-0003-0048-4976 \\ Universidade Federal do Pará, Brasil \\ E-mail: pimenteladelma@gmail.com \\ Maria de Nazareth Rodrigues Malcher de Oliveira Silva \\ ORCID: https://orcid.org/0000-0003-4405-7378 \\ Faculdade Ceilândia, Brasil \\ Universidade de Brasília, Brasil \\ E-mail: malchersilva@unb.br
}

\begin{abstract}
Resumo
Objetivo: apresentar repercussões psicológicas em adultos ante expectativa de acometimento pelo Corona vírus. Método: estudo qualitativo narrativo interpretativo. Resultados: o estudo apontou a preocupação e medo de $96 \%$ dos participantes em ser atacado pelo Corona vírus; e 4\% disseram que não; tais indicadores assinalam a percepção da gravidade da doença, sobretudo dos possíveis efeitos derivados das comorbidades; portanto, a aflição dos participantes independeu do gênero, e a narrativa demonstrou a magnitude do sofrimento manifesto na esfera da saúde psicológica e mental ressaltando ansiedade, pânico e depressão, estresse, temor, medo, falta de ar, taquicardia, aperto no peito, formigamentos, queda ou elevação da pressão arterial, dor de cabeça como sintomas psicossomáticos associados e derivados das emoções descritas e potencializadas pelas notícias veiculadas nos telejornais brasileiros e redes sociais virtuais. Há, ainda sintomas físicos: dor muscular, "embrulhos no estômago"; tensão; sobrepeso e anorexia. Quanto ao humor, agravou-se a impaciência, irritabilidade e sensação de impotência. Conclusão: O significado da palavra expectativa depreendido nas narrativas remete a uma antítese vivida cotidianamente, ou seja, transitar entre a possibilidade do acometimento da Covid-19, o adoecimento dos entes queridos; e a esperança da vacinação como fonte de cura e de superação das incertezas, dos pensamentos irracionais que nutrem o medo e a ansiedade.
\end{abstract}

Palavras-chave: Emoções; Sofrimento; Corona vírus.

\begin{abstract}
Objective: to present psychological repercussions for adults before the expectation of being affected by the Corona virus. Method: qualitative narrative interpretive study. Results: the study pointed out $96 \%$ of the participants' concern and fear of being attacked by the Corona virus; and $4 \%$ said they didn't; such indicators point to the perception of the severity of the disease, especially of the possible effects derived from comorbidities; therefore, the distress of the participants was independent of gender, and the narrative demonstrated the magnitude of the suffering manifested in the sphere of psychological and mental health, highlighting anxiety, panic and depression, stress, fear, fear, shortness of breath, tachycardia, tightness in the chest, tingling., fall or rise in blood pressure, headache as psychosomatic symptoms associated with and derived from the emotions described and enhanced by the news on Brazilian news and virtual social networks. There are also physical symptoms: muscle pain, "stomach wraps"; voltage; overweight and anorexia. As for humor, impatience, irritability and a feeling of helplessness worsened. Conclusion: The meaning of the word expectation understood in the narratives refers to an antithesis experienced on a daily basis, that is, to move between the possibility of the Covid-19 being affected, the illness of loved ones; and the hope of vaccination as a source of cure and overcoming uncertainties, irrational thoughts that nourish fear and anxiety.
\end{abstract}

Keywords: Emotions; Suffering; Corona virus.

\section{Resumen}

Objetivo: presentar repercusiones psicológicas en adultos ante la expectativa de ser afectados por el virus Corona. Método: estudio narrativo interpretativo cualitativo. Resultados: el estudio señaló el 96\% de la preocupación y el miedo de los participantes a ser atacados por el virus Corona; y el 4\% dijo que no; dichos indicadores apuntan a la percepción de la gravedad de la enfermedad, especialmente de los posibles efectos derivados de las comorbilidades; por tanto, la angustia de los participantes fue independiente del género, y la narrativa demostró la magnitud del sufrimiento manifestado en el ámbito de la salud psicológica y mental, destacando ansiedad, pánico y depresión, estrés, miedo, miedo, disnea, taquicardia, opresión en el pecho, hormigueo, descenso o aumento de la presión arterial, dolor de cabeza como síntomas psicosomáticos 
asociados y derivados de las emociones descritas y potenciadas por las noticias en las noticias brasileñas y las redes sociales virtuales. También hay síntomas físicos: dolor muscular, "envolturas de estómago"; Voltaje; sobrepeso y anorexia. En cuanto al humor, la impaciencia, la irritabilidad y el sentimiento de impotencia empeoraron. Conclusión: El significado de la palabra expectativa entendida en las narrativas se refiere a una antítesis vivida a diario, es decir, transitar entre la posibilidad de que el Covid-19 se vea afectado, la enfermedad de los seres queridos; y la esperanza de la vacunación como fuente de curación y superación de incertidumbres, pensamientos irracionales que alimentan el miedo y la ansiedad.

Palabras clave: Emociones; Sufrimiento; Coronavirus.

\section{Introdução}

Este texto apresenta os resultados de uma pesquisa qualitativa realizada com adultos de 18 a 59 anos, objetivando identificar repercussões psicológicas ante a expectativa de acometimento pela COVID-19, pandemia mundial que começou em 2020 e se configura como um acontecimento gerador de estresse, medo intenso, ansiedade, pânico, depressão, entre outros quadros clínicos, ocasionando sofrimento psicológico no âmbito da saúde mental, em grande parte da população afetada pelo Corona vírus. Assim, em março de 2020, o Departamento de Saúde Mental da Organização Mundial da Saúde (OMS) lançou um documento com 31 orientações para profissionais de saúde; gerentes de unidades de saúde; prestadores de cuidados a crianças, idosos, pessoas com doenças pré-existentes; e aos que estão isolados preconizando a prática da atitude empática nas relações interpessoais. O documento aponta os benefícios de ajudar outras pessoas, como telefonar para vizinhos ou membros da comunidade que possam precisar de assistência extra: "Trabalhar juntos como uma comunidade pode ajudar a criar solidariedade na abordagem à COVID-19." (OMS, 2020a, 2020b).

Empatia, solidariedade e compreensão integram o arcabouço social fundamental que as instituições de saúde mental precisam se valer para oferecer suportes externos as pessoas, atingidas e as não atingidas pelo Corona vírus, o que contribui para que elas fortaleçam seus suportes internos como o autoconceito, a esperança, otimismo, inteligência emocional, e força para tomar decisões para enfrentar o isolamento social.

Em 2021, a pandemia pode ser sintetizada como uma enfermidade gravíssima que prossegue gerando decorrências físicas e psicológicas em milhões de pessoas ao redor do mundo, sobretudo pela ausência de medicação efetiva, e pelas mutações do Corona vírus. Concomitantemente, grandes indústrias farmacêuticas avançam na produção da vacina e de medicamentos específicos para controle do vírus. Existem pelo menos 165 vacinas sendo desenvolvidas atualmente, segundo a OMS. Por exemplo, a China produz a Sinovac, a Sinophram e a CanSino; a Rússia a Sputnik; nos Estados Unidos da América a empresa de mesmo nome, produz a vacina Moderna; e outra pela coalizão de três empresas BioNtech/Pfizer/Fosun (Universidade do Sistema Único de Saúde [UNASUS], 2020). Ressaltamos, ainda que, em dezembro de 2020 foi aprovada, no Reino Unido a vacina de Oxford-AstraZeneca (FIOCRUZ, 2020). E no Brasil começou a fase três dos estudos clínicos da Butanvac. (Butantan,2020).

\section{Método}

A pesquisa é de orientação qualitativa configurada como um estudo qualitativo narrativo interpretativo. Foi aprovada pela CONEP sob o número do parecer: 4.008.456. Os colaboradores do estudo foram mulheres e homens adultos: professores, alunos e técnicos administrativos convidados para participar do estudo, por meio de convite postado em página do Facebook. Buscamos identificar repercussões emocionais ante expectativa de acometimento pela COVID-19, uma doença, cujo tratamento os cientistas estão labutando para enfrentar, tratar e curar (Pimentel \& Malcher, 2020; Fundação Oswaldo Cruz [Fiocruz], 2020).

Após aceitar o convite, os participantes responderam a um questionário no Google docs. A coleta foi realizada em junho e julho de 2020. As questões enfocaram idade; sexo/gênero; escolaridade; estado civil; com quem vive; estado emocional; sintomas psicológicos; impactos do isolamento social na saúde emocional. Solicitou-se aos participantes que colocassem o endereço eletrônico, caso desejassem receber os resultados da pesquisa, o que teve adesão plena da amostra. Para as análises, os dados das 
questões fechadas foram organizados descritivamente por percentual; e para as questões abertas priorizamos a busca dos sentidos, com base a inspiração fenomenológica hermenêutica da linguagem, que permite identificar estruturas significativas da experiência, e desvelar modos de produção de sentidos, por meio dos atos e funções da fala transformada em texto (Ricoeur, 1999). A apresentação das narrativas se dá explicitando o que as mulheres responderam, seguida das respostas dos homens. Para ambos usamos pseudônimos.

\section{Resultados e Discussão}

Em relação aos dados sociodemográficos dos 124 participantes do estudo $78 \%$ se declararam mulheres e $22 \%$ se afirmaram homens. Destes, a idade média corresponde a 18 a 59 anos, perfazendo 94,3\% dos colaboradores. Não foram inclusas nas análises respostas de pessoas com mais de 60 anos, o que corresponde a 5,7\%. A escolaridade grau superior das mulheres foi de $86,2 \%$ e a dos homens de $97,3 \%$. Quanto ao estado civil, $45,2 \%$ eram solteiros; $37,1 \%$ casados; $8,9 \%$ divorciados; $6,5 \%$ em união estável; $1,6 \%$ viúvos; $0,7 \%$ não informou. Sobre a preocupação em ser atacado pelo Corona vírus, $96 \%$ dos participantes da pesquisa (homens e mulheres) afirmaram que sentiam medo e $4 \%$ disseram que não. Deste modo foi integral a inquietação em ser atacado pelo Corona vírus.

Sem compor heurísticas plenas sobre gêneros, incluímos alguns comentários específicos sobre a saúde mental de mulheres, pois do total de respondentes, $78 \%$ foram mulheres e $22 \%$ homens, resultado que se assemelha ao da pesquisa sobre COVID-19 realizada no Rio Grande do Sul por Duarte, Santo, Lima, Giordani e Trentini (2020), em que o escore foi de 82,7\% de mulheres. Santo e Diniz (2018) descreveram "Estudos epidemiológicos em que apontam para uma inegável diferença de gênero quanto à incidência, prevalência e curso de transtornos mentais. Tanto as condições orgânicas, quanto, principalmente, as realidades sociais às quais as mulheres estão submetidas, favorecem um ambiente interno propício a uma maior ocorrência de problemas psicológicos, tais como depressão, ansiedade, distúrbios alimentares e transtornos associados ao ciclo reprodutivo" (p.29).

Importante compreender que a saúde mental de mulheres não pode se dar apenas por enfoques biologizantes, com argumentação linear e de signos psicopatológicos, mas, efetivar-se por uma abordagem complexa em diversas dimensões e interdisciplinar, como por exemplo em contexto da dimensões das tarefas ocupacionais, nas diferentes jornadas de trabalho; a busca por desenvolvimento pessoal e profissional, a resposta as pressões do mercado da beleza; o racismo estrutural; e a geracionalidade, entre outros. Ou seja, a sociabilidade no percurso são também fatores de riscos à saúde mental.

Além das mulheres, a vida de todos os gêneros é afetada pela COVID-19. Oda e Leite (2020) no editorial da Revista Latinoamericana de Psicopatologia Fundamental evocam alguns sentidos da pandemia da COVID-19 no Brasil, comentando sobre a indiferença, o descaso, o entorpecimento, as consequências a longo prazo na saúde física e mental das pessoas. Para Vasconcelos, Feitosa, Medrado e Brito (2020, p77), “As epidemias podem levar ao surgimento de sintomas psicológicos em pessoas que antes não os tinham, podendo agravar sintomas em pessoas com condições pré-existentes e causar sofrimento aos cuidadores de pessoas doentes". Schmidt, Bolze, Neiva-Silva, e Demenech (2020, p 9) em revisão narrativa apontam que na população em geral, "Pessoas com suspeita de infecção pelo coronavírus podem desenvolver sintomas obsessivo-compulsivos"; e os profissionais de saúde sentem "Frustração por não conseguir salvar vidas, apesar dos esforços; Sobre a COVID-19, os desafios enfrentados podem ser um gatilho para o desencadeamento ou a intensificação de sintomas de ansiedade, depressão e estresse” (p.10).

\subsection{Repercussões psicológicas da Covid-19 nas mulheres}

As repercussões básicas descritas pelas mulheres foram os sentimentos de temor, medo, ansiedade e preocupação ante a possibilidade de ser atingidas pelo Corona Vírus, bem como os seus familiares e amigos. A narrativa de Sandra indica sua afetação psicológica, em que medo e ansiedade podem ser observados, semelhantes aos resultados apontados em Maia e Dias (2020) na 
pesquisa sobre ansiedade, depressão e estresse em estudantes universitários portugueses relacionados a pandemia da COVID-19, “Os principais fatores de estresse, sobressaem com a duração da quarentena, os receios em relação ao vírus ou à infeção, a frustração, a diminuição de rendimentos, a informação inadequada e o estigma” (p.2). Para Marcela, a ênfase se deu nos sentimentos de solidão e medo; além dos sintomas físicos como dor no coração, associado a ansiedade,

Estou em tratamento psicoterápico. Houve piora no meu quadro após Pandemia; Se em certo momento começo a tossir, fico preocupada achando ser sintoma da Covid-19; Dores de cabeça e nas articulações; insônia; tenho muita apatia por não conseguir ver as coisas "andando" e ansiedade por não conseguir imaginar um futuro. (Sandra)

Venho me sentindo sozinha há muito tempo, as vezes quando estou acordada de madrugada, sinto meu coração doer, mas não é essas dores que realmente sentimos. Não sei explicar, me pergunto o que isso significa. Só queria voltar a me sentir bem novamente. Sinto medo de ser infectada na atual situação de colapso, porque não sei como será meus sintomas. Isso causa medo. (Marcela)

Por sua vez, Cristina pontuou uma preocupação mais intensa com seus pais e família que continuam trabalhando fora de casa, podem adoecer, contaminá-la, e talvez morrerem. Sente, ainda a falta das atividades sociais que realizava antes do isolamento social, cuja ausência lhe traz saudades e confusão emocional,

Sinto medo de alguém da família se contagiar, meus pais e irmãos estão trabalhando porque é necessário, eu e minhas irmãs somos as únicas a ficar em casa. Me dá medo que algum deles traga o vírus pra casa, me sinto angustiada sempre que saem para trabalhar, porque não sei se irão retornar. Ultimamente eu tenho misturado muitas emoções do meu passado na minha vida atualmente, isso me frusta, pois não sei se sinto isso realmente, ou então sinto falta de sentir. (Cristina)

As narrativas apontaram a necessidade das participantes obterem mais cuidados no trabalho para proteção física contra o vírus; e na esfera do estado, por exemplo, o governo, ao melhorar a comunicação com a população poderia esclarecer as pessoas da gravidade do vírus, bem como oferecer equipamentos de proteção individual. As participantes consideram que tais medidas ajudálas-iam a sentir-se protegidas em relação a sua saúde emocional. Como disse Margareth,

Eu particularmente mantenho minha saúde emocional me livrando dos noticiários, evitando ver coisas que venham mexer com o meu psicológico, tento não ir a fundo em relação a isso. Alimento minha saúde emocional lendo um livro assistindo desenho e por fim orando todas as noites. Deixar de assistir noticiários de quantitativo de morte. (Margareth)

A participante Marilia elenca a importância do conhecimento cientifico como fator de cura da COVID-19 pela produção de vacinas e remédios; e Gisele indica a necessidade de apoio psicológico,

A cura; os remédios, que essa pandemia que estamos vivendo passe logo; ter soluções científicas - vacina contra o mesmo. (Marília)

Psicoterapia, apoio psicológico ajudaria a redimensionar; mesmo em tratamento tenho medo. Relaxamento, reflexão, controle da respiração. Manter pensamentos e sentimentos alinhados as questões reais. Controlar minha ansiedade. (Gisele)

Outro indicador importante descrito foi a vinculação ao transcendente, pois a fé em Deus é um suporte para a vida de Laís, bem como as santas da igreja Católica,

A fé me dá força em Deus e calma. Sou Católica e tenho muita fé em Deus e Nossa Senhora. Quando estou firme em oração me sinto bem, confiante e tranquila pra enfrentar os desafios; que independente de tudo o que vou viver terei a força necessária para reagir e tomar todas as decisões para me sentir a serviço de quem precisar. (Laís) 
No quesito consumo de informações sobre o Corona Vírus, Sônia se queixou que as redes sociais virtuais disseminam conteúdos inadequados, o que a levou a um afastamento provisório das mesmas no contexto da pandemia, já que, nas mesmas há mais intolerância, e atritos que empatia e acolhimento, o que afeta sua saúde mental com aumento da ansiedade,

Percebi que a demanda de informações que estava consumindo por redes sociais estava me prejudicando, e preferi excluir tais redes sociais e apenas filtrar o que importa nesse momento. Isso diminuiu muito minha ansiedade. Pratico meditação diariamente que fortalece muito minha saúde emocional. Empatia, porém, essa é uma palavra muito difícil de ser praticada. (Sônia)

E por fim, a narrativa de Rafaela assinala uma consequência grave da pandemia: o isolamento e a solidão a que está submetida instalaram um distúrbio alimentar, referindo que comer, em situações emocionalmente desconfortáveis, é uma estratégia conhecida e praticada por ela, o que requer cuidados clínicos imediatos,

Como moro longe da família, acho que a saudade e as vezes a solidão machucavam mais; sinto que estou descontando todos as minhas frustrações na comida como já fiz muitas vezes. Não consigo criar forças para tentar cosias novas, não me concentro em nada; livros que eu amava, $n$ consigo prosseguir e isso me frustra muito. Medo de quando isso acabar eu ter que arrumar tanta coisa em mim psicologicamente, financeiramente e fisicamente q parece uma bola de neve. Me pego chorando no quarto. Nível de estresse altíssimo também. (Rafaela)

Consideramos que as manifestações psicológicas em destaque foram de medo, ansiedade, com um pequeno desdobramento em depressão e transtorno do pânico em mulheres que relataram não ter sido atingidas. Em outras que foram acometidas pela COVID 19 permaneceu a preocupação, a tristeza e o medo de morrer, com redução de ansiedade. Assim, sistematizamos as percepções das vivencias do sofrimento psíquico das colaboradoras na Figura 1,

Figura 1. Percepções das vivencias do sofrimento psíquico - Ansiedade.

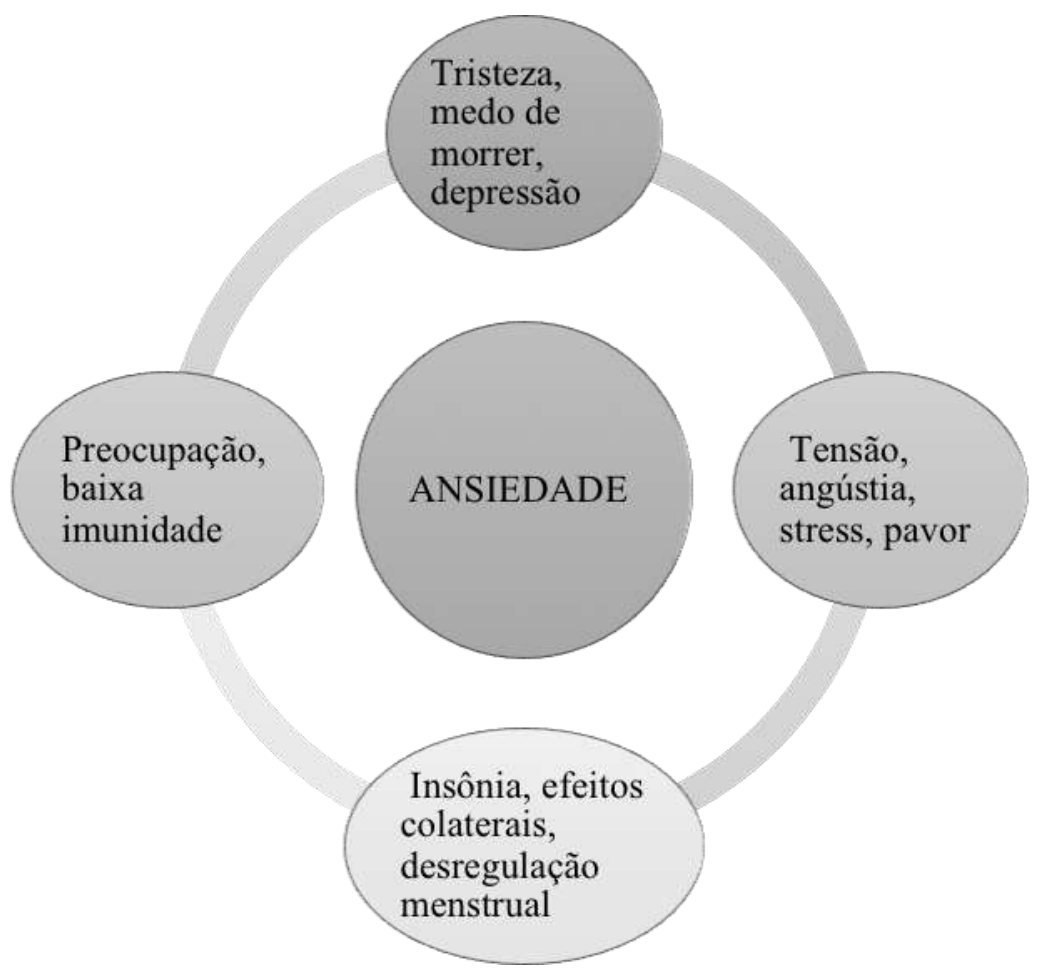

Fonte: Pesquisa (2020). 


\subsection{Repercussões psicológicas da Covid-19 nos homens}

As repercussões básicas descritas pelos homens foram os sentimentos de desequilíbrio pessoal; preocupação; e também sintomas físicos. Ressaltamos que dois relataram que foram acometidos pela COVID 19, e um faz psicoterapia online. A narrativa de Sérgio assinala um aspecto importante sobre a sua concepção da natureza humana, que para ele é permeada pela "maldade", o que contribui para a desinformação que circula nos meios de comunicação massivos e pós-massivos pelo abuso econômico de comerciantes e políticos, na gestão dos insumos necessários ao tratamento da COVID-19. Afirmou que procura relaxamento na atividade física, na arte e assistir filmes,

Ocupar a mente nos "horários vagos" com desenhos animados, filmes de comedia, cuidar dos nossos animais, dos filhos, esposa e netos. Sair um pouco do furacão do excesso de informações, racionalizar sem me contaminar com a toxicidade da maldade humana, pois nós da área de saúde e do atendimento de ponta, sabemos que essa maldade humana está sendo em grande parte, a norteadora do aumento de casos e das mortes. Porque vejo os interesses financeiros/políticos/empresarial/"religioso" \$\$\$... Distrações artísticas e exercício físico (Sérgio)

Acerca dos impactos do isolamento social, Cezar mencionou perplexidade ante a pandemia, intensa frustração pois estava em vias de abrir uma empresa. Pontua que suas dificuldades intimas de comunicar-se e interagir socialmente se agravaram o que provoca angustia, ansiedade e tristeza,

Estava esperançoso e com muita vontade de investir numa empresa. Eu acho isso tudo que estamos vivendo muito louco, jamais pensaria em algo assim. Sentir saudade de estar com as pessoas que amo é uma constante que só falta rasgar o peito! Comunicação via internet não é o suficiente as vezes, e eu pioro muito a situação pois, eu já era ruim em me comunicar, mas tento não me cobrar tanto também... não só nesse quesito como em outros. Tem dias que me sinto horrível por não fazer nada e dias que o cansaço reina por ter feito tanto. (Cezar)

Cezar, ainda indica a esperança na atualização das formas de consciência que as pessoas podem desenvolver no contexto da pandemia,

Sei que não vamos "voltar ao normal" depois que isso passar, espero que voltemos com mais consciência coletiva, sabendo dar valor as pessoas que realmente importam e aos momentos que passamos juntos. (Cezar)

Por sua vez, Carlos demonstrou senso crítico ao modo que a sociedade ocidental se movimenta, ao revelar que considera a pandemia uma consequência natural de um estilo de vida exploratório; censura as posturas negacionistas de algumas pessoas e destaca a importância da ciência; e completa mencionado o medo da doença,

Enxergo a pandemia como algo natural e totalmente previsível perante à ciência, porém nunca estamos preparados dos impactos do isolamento, haja vista que ainda temos muitos negacionistas em nossa sociedade que acabam prejudicando à retomada gradual das atividades em sua totalidade. Infelizmente meu maior medo é no impacto que isto pode causar no meu círculo próximo. A sociedade já não será mais a mesma, e devemos encarar isto de frente para os novos desafios que virão numa era pós isolamento. (Carlos)

As percepções da expectativa de ser acometido pelo Corona Vírus para os homens evidenciou, de modo semelhante as mulheres, ansiedade. Assim, sistematizamos na Figura 2 as manifestações expressas: 
Figura 2. Diferenças descritas em volume e áreas de expressividade da ansiedade.

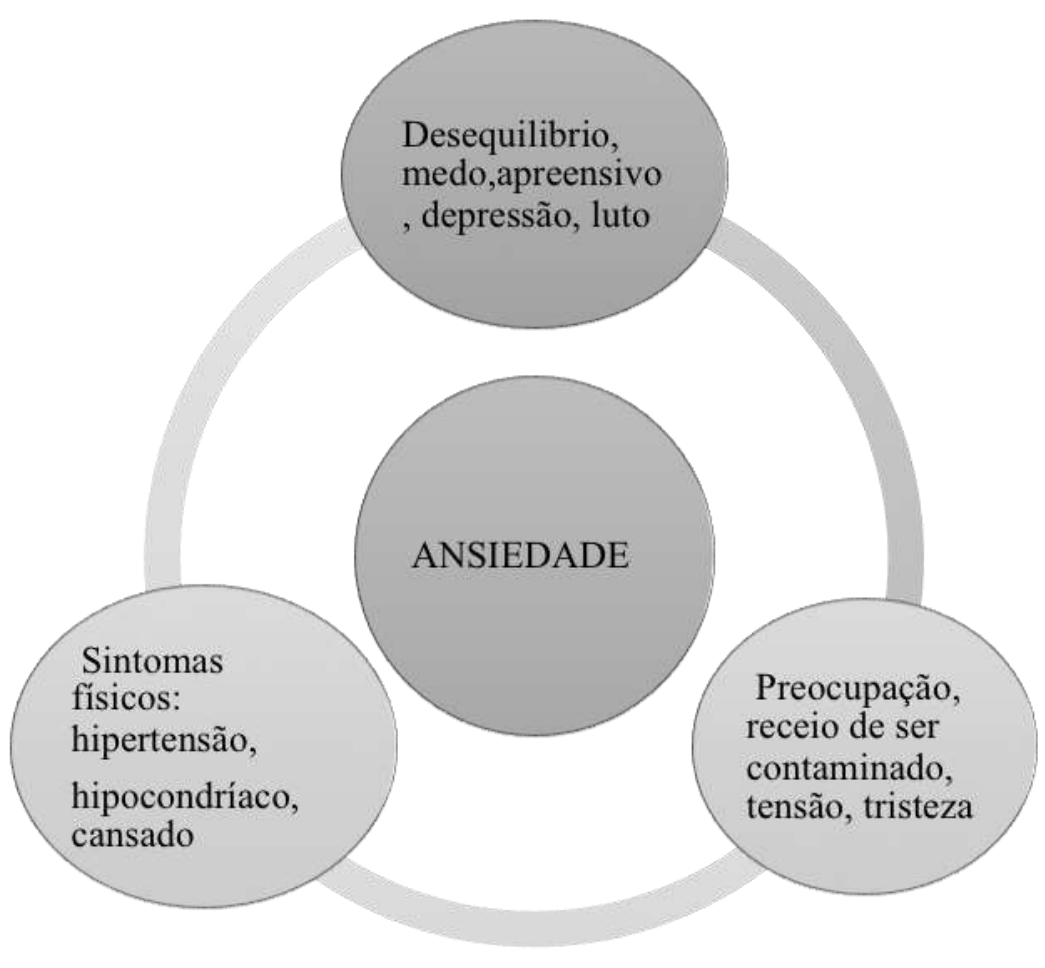

Fonte: Pesquisa (2020).

\section{Considerações Finais}

A pesquisa permitiu aclarar alguns dos impactos psicologicos na saúde, ante a possibilidade do acometimento pelo Corona vírus em mulheres e homens 18 a 59 anos. Ansiedade, pânico e depressão foram manifestações psicológicas comuns descritas nas respostas dos participantes do estudo; somados ao estresse, temor, medo, falta de ar, taquicardia, aperto no peito, formigamentos, queda ou elevação da pressão arterial, dor de cabeça como sintomas psicossomáticos associados e derivados das emoções vividas, e potencializadas pelo volume máximo e diário de notícias veiculadas em todos os telejornais brasileiros e redes sociais virtuais.

O significado da palavra expectativa depreendido nas narrativas remete a uma antítese vivida cotidianamente, ou seja, transitar entre a possibilidade do acometimento da Covid-19, o adoecimento dos entes queridos; e a esperança da vacinação como fonte de cura e de superação das incertezas, dos pensamentos irracionais que nutrem o medo e a ansiedade.

A magnitude do sofrimento humano foi nítida nos relatos. Sobre a preocupação dos participantes em ser atacado pelo Corona vírus, 96\% afirmaram que sentiam medo, o que aponta a percepção da gravidade da doença, sobretudo dos possíveis efeitos derivados das comorbidades; portanto, a aflição dos partícipes independeu do gênero, e a narrativa demonstrou a magnitude do sofrimento humano manifesto na esfera da saúde psicológica e mental.

Ensejamos que o estudo contribua para que profissionais da saúde desenvolvam estratégias interventivas no âmbito da psicoterapia e de práticas de conscientização corporal como relaxamento e yoga. A sua relevância está em oferecer elementos empíricos que podem contribuir para a elaboração de planos de intervenção em psicologia clínica e de políticas públicas. A expectativa ante a proximidade - imaginada e real do acometimento pela COVID-19 foi intensa, sendo que, todos os colaboradores ressaltaram a vivencia do sofrimento psicológico, conexo as incertezas vividas no presente.

\section{Referências}

Testes confirmam que a vacina do Butantan é a mais segura e eficaz em fase final no Brasil. (2020). https://butantan.gov.br/noticias/testes-confirmam-que-vacinado-butantan-e-a-mais-segura-em-fase-final-no-brasil 
Research, Society and Development, v. 10, n. 4, e39810414151, 2021 (CC BY 4.0) | ISSN 2525-3409 | DOI: http://dx.doi.org/10.33448/rsd-v10i4.14151

Duarte, M. de Q., Santo, M. A. S., Lima, C. P., Giordani, J. P., \& Trentini, C. M. (2020). COVID-19 e os impactos na saúde mental: uma amostra do Rio Grande do Sul, Brasil. Ciência \& Saúde Coletiva, 25(9):3401-3411.

Fundação Oswaldo Cruz. (2020). Fiocruz divulga contrato de encomenda tecnológica com a Astrazeneca. Consultado em: 12 de janeiro de 2021. https://portal.fiocruz.br/noticia/fiocruz-divulga-contrato-de-encomenda-tecnologica-com-astrazeneca

Fundação Oswaldo Cruz. (2021). Vacinas contra Covid 19. https://portal.fiocruz.br/vacinascovid19

Maia, B. R., \& Dias, P. C. (2020). Ansiedade, depressão e estresse em estudantes universitários: o impacto da COVID-19. Estudos de Psicologia, 37, e200067. http://dx.doi.org/10.1590/1982-0275202037e200067

Organização Mundial de Saúde. (2020a). Guia com cuidados para saúde mental durante a pandemia. 2020a. https://news.un.org/pt/story/2020/03/1707792

Organização Mundial de Saúde. (2020b). Coronavirus disease 2019 (COVID-19): Situation Report-51. https://www.who.int/docs/default- source/coronaviruse/sit uation-reports/20200311-sitrep-51-covid-19.pdf?sfvrsn=1ba62e57_10

Pimentel, A, Silva, M. N. (2020). Saúde psíquica em tempos de Corona vírus. Research, Society and Development, 9(7), e11973602. http://dx.doi.org/10.33448/ rsd-v9i7.3602

Ricoeur, P. (1999). Teoria das interpretações. Edições 70.

Santos e Diniz (2018) Saúde mental de mulheres donas de casa: um olhar feminista-fenomenológico-existencial. Psic. Clin., $30(1), 37$ - 59.

Schmidt, B., Crepaldi, M. A., Bolze, S. D. A., Neiva-Silva, L., \& Demenech, L. M. (2020). Saúde mental e intervenções psicológicas diante da pandemia do novo coronavírus (COVID-19). Estudos de Psicologia (Campinas), 37.

Oda, A. M. G. R. \&, Leite, S. (2020). A pandemia de COVID-19 no Brasil: em busca de sentidos em meio à tragédia. Rev. Latinoam. Psicopat. Fund., 23(3), 467473.

Vasconcelos, C. S. da S. F., Medrado, P. L. R., Brito, A. P. B. I. de O. O novo coronavírus e os impactos psicológicos da quarentena. Revista Desafios - 7 COVID-12. 